\title{
EFICIÊNCIA E DESEMPENHO OPERACIONAL DE MÁQUINAS HARVESTER E FORWARDER NA COLHEITA FLORESTAL ${ }^{1}$
}

\author{
Mariana Linhares², Carlos Roberto Sette Júnior³, Fernando Campos², Fábio Minoru Yamaji ${ }^{4}$
}

\begin{abstract}
HARVESTER AND FORWARDER MACHINES EFFICIENCY AND OPERATIONAL PERFORMANCE IN FOREST HARVESTING

The knowledge on productive capacity and variable elements that affect machines efficiency is essential for optimizing operations in forest harvesting. This study aimed to evaluate Harvester and Forwarder machines efficiency and operational performance, for forest exploitation, in the south of the Bahia State, Brazil. Data concerning the number of programmed and effective working hours, as well as reasons for machine downtime, were collected from historical archives, from October 2010 to September 2011. Based on these data, the total working hours, operational efficiency, and mechanical availability were calculated. Harvester machines showed an average of total working hours of 480 hours and 18 minutes, being $75.6 \%$ (363.2 hours) of effective work and $24.4 \%$ (117.1 hours) of downtime. Forwarder machines showed an average of total working hours of 481 hours and 36 minutes, being $84.7 \%$ (407.9 hours) of effective work and $15.3 \%$ ( 73.7 hours) of downtime. The average operational efficiency was of $73.2 \%$, for the Harvester, and $82.2 \%$, for the Forwarder, and technical downtimes, such as displacements and corrective and preventive maintenances, comprised the main reason for explaining those values. The machines operational performance showed to be adequate, according to time distribution, with $76 \%$ and $85 \%$ of effective working time, respectively for the Harvester and Forwarder, and an average of $89 \%$ for mechanical availability, for both machines, which showed satisfactory operational efficiency (above 70\%).
\end{abstract}

KEY-WORDS: Forestry machines; timber harvesting; forest exploitation.

\section{INTRODUÇÃO}

No início das atividades de reflorestamento, no Brasil, poucas empresas utilizavam a mecanização nas operações de colheita florestal. A partir da década de 1990, com a abertura das importações, o aumento do

\section{RESUMO}

O conhecimento da capacidade produtiva e das variáveis que interferem no rendimento das máquinas é fundamental para a otimização das operações na colheita florestal. O objetivo deste trabalho foi avaliar o desempenho operacional e a eficiência de máquinas Harvester e Forwarder, utilizadas na exploração florestal, no sul da Bahia. Foram utilizados dados do número de horas programadas e efetivas de trabalho das máquinas e motivos de paradas, obtidos de arquivos históricos, de outubro/2010 a setembro/2011. Com base nestes dados, foram calculadas as horas totais de trabalho, eficiência operacional e disponibilidade mecânica das máquinas. As máquinas Harvester apresentaram média de horas totais de trabalho de 480 horas e 18 minutos, sendo $75,6 \%$ (363,2 horas) de horas efetivas e $24,4 \%$ ( 117,1 horas) de horas paradas. As máquinas Forwarder apresentaram média de horas totais de trabalho de 481 horas e 36 minutos, sendo $84,7 \%$ ( 407,9 horas) de horas efetivas e 15,3\% (73,7 horas) de horas paradas. A eficiência operacional média foi de $73,2 \%$, para a Harvester, e de $82,2 \%$, para a Forwarder, sendo que as paradas técnicas, como deslocamentos e manutenções preventivas e corretivas, foram as principais causas de influência nestes valores. O desempenho operacional das máquinas mostrou-se adequado, em função da distribuição dos tempos, com $76 \%$ e $85 \%$ de tempo efetivo de trabalho, para a Harvester e Forwarder, respectivamente, e média de $89 \%$ para disponibilidade mecânica, para ambas as máquinas, as quais apresentaram eficiência operacional satisfatória (acima de 70\%).

PALAVRAS-CHAVE: Máquinas florestais; colheita de madeira; exploração florestal.

custo da mão de obra e a necessidade de se executar o trabalho de forma mais ergonômica e com maior eficiência, as empresas iniciaram a mecanização das operações de colheita de forma mais intensiva (Machado 2008).

A colheita e o transporte são atividades de grande importância no setor florestal, dados os riscos

1. Trabalho recebido em jan./2012 e aceito para publicação em jun./2012 ( $\mathrm{n}^{\circ}$ registro: PAT 16921).

2. Ponsse Latin America, Mogi das Cruzes, SP, Brasil.E-mails: mariana.linhares@ponsse.com, fernando.campos@ponsse.com.

3. Universidade Federal de Goiás, Escola de Agronomia e Engenharia de Alimentos, Goiânia, GO, Brasil.

E-mail: crsettejr@hotmail.com.

4. Universidade Federal de São Carlos, Departamento de Ciências Ambientais, Sorocaba, SP, Brasil.E-mail: fmyamaji@ufscar.br. 
de perdas envolvidos nestas atividades (Machado \& Lopes 2000) e o elevado custo do produto final, podendo representar mais de $50 \%$ do preço da madeira que chega à indústria (Bagio \& Stohr 1978, Machado 1989).

A realização de estudos que visem a conhecer a capacidade produtiva e as possíveis variáveis que interferem no rendimento de máquinas e equipamentos da colheita florestal tornou-se uma preocupação crescente das empresas florestais, visando ao desenvolvimento de técnicas que melhorem o desempenho operacional e a eficiência das máquinas, maximizando a produtividade e reduzindo os custos de produção (Silva et al. 2003).

O planejamento operacional das atividades florestais tem por objetivo estabelecer alternativas que propiciem o cumprimento das metas de produção que são determinadas pelo planejamento global da empresa, por meio do conhecimento da eficiência e do desempenho operacional das máquinas e equipamentos utilizados na colheita florestal (Cechin 2000).

A eficiência de um sistema de colheita de madeira depende, basicamente, do ambiente onde o mesmo é trabalhado, e os principais fatores a serem considerados são o clima, o terreno, a espécie vegetal, a infraestrutura, o nível de desenvolvimento, a tradição do sistema utilizado e a estrutura da indústria (Andersson \& Laestadius 1987, Malinovski \& Liotto 1992, Malinovski \& Malinovski 1998).

Os principais fatores que influenciam no desempenho operacional das máquinas, em relação ao operador, são, segundo Cechin (2000), as horas de alimentação (lanches e água), descanso e higiene pessoal, o tempo de experiência e o estado de ansiedade do trabalhador, obstáculos presentes no percurso das máquinas, velocidade de deslocamento da máquina e paradas técnicas para manutenção e reparos.

Os sistemas de colheita de madeira, de acordo com a matéria-prima, podem ser classificados em: (i) toras curtas, (ii) toras longas, (iii) árvores inteiras e (iv) árvores completas (Machado 2008).

No sistema de toras curtas, todas as atividades complementares ao corte (desgalhamento, destopo, toragem e descascamento) são realizadas no local de derrubada das árvores. Entre as vantagens deste sistema, estão a facilidade de deslocamento e a baixa agressão ao meio ambiente, principalmente em relação à ciclagem de nutrientes no solo. Atualmente, este sistema é utilizado pelas maiores empresas que trabalham com plantios homogêneos de pinus e eucalipto, no Brasil (Machado 2008).

Dentre as máquinas mais utilizadas na exploração florestal, estão a Harvester, que é um trator derrubador, desgalhador, traçador e empilhador, e a Forwarder, que é um trator florestal, cuja função é realizar o transporte primário por autocarregamento/ descarregamento.

O objetivo deste trabalho foi avaliar o desempenho operacional e a eficiência dos equipamentos Harvester e Forwarder, utilizados na exploração de povoamentos florestais localizados na região sul do Estado da Bahia.

\section{MATERIAL E MÉTODOS}

O estudo foi realizado com máquinas desenvolvendo trabalhos em povoamentos de Eucalyptus grandis de uma empresa do setor florestal, localizados na região sul do Estado da Bahia $\left(16^{\circ} 22^{\prime} \mathrm{S}\right.$ e $\left.39^{\circ} 34^{\prime} \mathrm{W}\right)$. O clima predominante na região é do tipo Af, com verão chuvoso e inverno seco, segundo a classificação climática de Köpen, que apresenta precipitação anual de, aproximadamente, $1.200 \mathrm{~mm}$, com temperatura média anual de $24,5^{\circ} \mathrm{C}$ (Leão \& Melo 1990). A altitude média da região é de $180 \mathrm{~m}$ e a cobertura vegetal natural é a floresta ombrófila densa, sob o domínio de Floresta Atlântica (Novaes \& São José 1992). Os solos encontrados nesta região são muito pobres, sendo mais comuns o Argissolo Vermelho-Amarelo, Latossolo Amarelo e Latossolo Vermelho-Amarelo (Embrapa 2006).

O sistema de colheita de madeira utilizado no corte raso do povoamento de eucalipto da empresa é o Cut-to-Length, composto pelas máquinas florestais Harvester e Forwarder, sendo a primeira responsável pelo corte, desgalhamento, descascamento e toragem e a segunda pelo carregamento e descarregamento das toras. A empresa possui um processo operacional de produção de celulose que vai do plantio de eucalipto, passando pela produção e logística da celulose, até a entrega do produto final ao cliente. A fábrica tem produzido cerca de 1,0 milhão de toneladas de celulose branqueada de eucalipto por ano, com idade média dos povoamentos de, aproximadamente, 5 anos.

A metodologia utilizada para avaliar o desempenho operacional e a eficiência das máquinas florestais foi a descrita por Cechin (2000), sendo utilizados os dados obtidos por meio dos arquivos históricos da 
empresa na análise do desempenho operacional e do grau de eficiência das máquinas.

Foram analisados os dados históricos de quatro Harvesters e quatro Forwarders, no período de outubro de 2010 a setembro de 2011. Em geral, a vida útil dos cabeçotes é de, aproximadamente, 12.500 horas (dois anos e meio), sendo que o tempo de vida das escavadoras e Forwarder são de, aproximadamente, cinco anos (25.000 horas). As máquinas florestais analisadas referem-se às que estavam em operação no período de realização do estudo, sendo que, em outubro de 2010 (início do estudo), elas eram novas, ou seja, sem horas de trabalho, e, no mês de setembro de 2011 (fim do estudo), após 1 ano em operação, as Harvesters apresentavam, em média, 4.500 horas e as Forwarders 5.000 horas de trabalho.

Os dados foram retirados dos relatórios mensais referentes às atividades florestais da empresa. Nestes, constavam o número de horas programadas para o trabalho das máquinas (horas da jornada de trabalho teórica diária multiplicada pelo número de dias programados para as máquinas trabalharem por mês: $\mathrm{Hpr}=(8+8) * 31$, sendo 2 turnos de 8 horas por dia, multiplicados por 31 dias (mês)); horas efetivas de trabalho (horas em que as máquinas estiveram realmente trabalhando durante o mês); e as horas paradas e os motivos pelos quais estas máquinas estiveram paradas (horas em que as máquinas ficaram paradas por mês, devido ao tempo de deslocamento, manutenção corretiva e preventiva e outros).

As horas totais de trabalho e a eficiência das máquinas foram calculadas a partir da equação $\mathrm{HT}=$ $\mathrm{HE}+\mathrm{PA}$, onde HT = horas totais de trabalho das máquinas no mês, $\mathrm{HE}=$ horas de trabalho efetivo das máquinas no mês e $\mathrm{PA}=$ horas em que a máquina esteve parada; e $\mathrm{E}(\%)=\mathrm{HE} / \mathrm{PR} \times 100$, onde $\mathrm{E}(\%)=$ percentagem de eficiência das máquinas, $\mathrm{HE}=$ horas de trabalho efetivo das máquinas no mês e $\mathrm{PR}=$ horas programadas para as máquinas trabalharem no mês.

O desempenho operacional das máquinas Harvester e Forwarder foi determinado por meio da análise das horas de trabalho das máquinas (horas programadas, efetivas e paradas) e da disponibilidade mecânica, que, segundo Simões \& Fenner (2010), é definida como o percentual do tempo de trabalho delineado à máquina mecanicamente apta a desenvolver suas operações, o qual consiste em se desconsiderar o tempo despendido para efetuar reparos ou manutenção, conforme a equação Dm $(\%)=$ $\mathrm{HE}-\mathrm{HM} / \mathrm{HE} \times 100$, onde $\mathrm{DM}=$ grau de disponibi- lidade mecânica (\%) e HM = tempo de interrupção para efetuar reparos ou manutenção (horas).

Nas análises estatísticas, foi aplicado o programa SAS (SAS Institute 1997), sendo aferidos os "outliers" e a heterogeneidade da variância. A análise de variância (ANOVA) foi aplicada para verificar o efeito das estações do ano no desempenho operacional e eficiência das máquinas florestais, e, quando significativa, foi utilizado o teste Tukey, a 5\%.

\section{RESULTADOS E DISCUSSÃO}

\section{Desempenho operacional e eficiência da Harvester}

As médias mensais das horas totais, efetivas, paradas e programadas de trabalho, disponibilidade mecânica e eficiência das Harvesters são ilustradas na Tabela 1. As máquinas apresentaram uma média de horas totais de trabalho mensal de 480 horas e 18 minutos, sendo $75,6 \%$ (363,2 horas) de horas efetivas e $24,4 \%$ (117,1 horas) de horas paradas. A média de horas totais de trabalho, de outubro de 2010 a setembro de 2011, foi 3,2\% menor que as 496 horas e 6 minutos programadas para serem realizadas mensalmente. Apesar disto, nos meses de fevereiro, abril, junho e setembro de 2011, as máquinas trabalharam mais do que o programado (cerca de 0,2-6,2\%). Tal fato resultou da necessidade de se aumentar o abastecimento de madeira da fábrica, nestes meses, e aos baixos níveis de precipitação observados neste período (Tabela 1), favorecendo o desempenho das máquinas.

O percentual do tempo de trabalho delineado à máquina mecanicamente apta a desenvolver suas operações (DM) foi similar, nos diferentes meses do período de avaliação (Tabela 1), fato, este, explicado pelo tempo despendido para se efetuar a manutenção corretiva das máquinas, durante a operação, que não diferiu, neste período. A disponibilidade mecânica média das máquinas Harvester foi de $86,6 \%$, sendo inferior ao encontrado por Silva et al. (2010), para a mesma máquina florestal $(90,3 \%)$. A disponibilidade mecânica das máquinas florestais está em torno de $92 \%$, para equipamentos novos, e $85 \%$, para equipamentos com maior tempo de uso (Fontes \& Machado 2002).

A medição e o controle do desempenho operacional das máquinas florestais são fundamentais para controlar e auxiliar na tomada de decisões, do nível estratégico ao operacional (Peloia \& Milan 2010). 
Tabela 1. Valores médios mensais de horas totais (HT), horas efetivas (HE), horas paradas (HP) e horas programadas (HPr) de trabalho, disponibilidade mecânica (DM) e eficiência operacional (E) de Harvesters utilizadas na colheita florestal e precipitação pluvial acumulada durante os meses de avaliação (BA, 2010/2011).

\begin{tabular}{|c|c|c|c|c|c|c|c|}
\hline \multirow{2}{*}{ Período } & HT & $\mathrm{HE}$ & $\mathrm{HP}$ & HPr & DM & $\mathrm{E}$ & \multirow{2}{*}{$\frac{\text { Precipitação }}{\mathrm{mm}}$} \\
\hline & \multicolumn{4}{|c|}{ horas - } & \multicolumn{2}{|c|}{$\%$} & \\
\hline Out/2010 & 320,0 & 251,3 & 68,7 & 496,0 & 89,0 & 50,7 & 207,6 \\
\hline Nov/2010 & 496,0 & 391,2 & 104,8 & 496,0 & 89,8 & 78,9 & 219,1 \\
\hline Dez/2010 & 492,0 & 379,6 & 112,4 & 496,0 & 88,9 & 76,5 & 77,6 \\
\hline $\operatorname{Jan} / 2011$ & 490,2 & 383,7 & 106,5 & 496,0 & 86,7 & 77,4 & 40,8 \\
\hline Fev/2011 & 526,7 & 370,6 & 156,2 & 496,0 & 85,4 & 74,7 & 28,5 \\
\hline Mar/2011 & 471,8 & 365,9 & 105,9 & 496,0 & 87,7 & 73,8 & 292,1 \\
\hline $\mathrm{Abr} / 2011$ & 520,1 & 380,2 & 140,0 & 496,0 & 85,9 & 76,6 & 64,9 \\
\hline Mai/2011 & 480,5 & 370,0 & 110,5 & 496,0 & 87,2 & 74,6 & 23,7 \\
\hline Jun/2011 & 497,0 & 363,0 & 134,0 & 496,0 & 85,3 & 73,2 & 1,8 \\
\hline Jul/2011 & 481,8 & 365,4 & 116,3 & 496,0 & 84,1 & 73,7 & 28,7 \\
\hline Ago/2011 & 489,3 & 349,8 & 139,4 & 496,0 & 82,6 & 70,5 & 18,0 \\
\hline Set/2011 & 497,8 & 387,2 & 110,6 & 497,8 & 86,5 & 77,8 & 2,0 \\
\hline Média & 480,3 & 363,2 & 117,1 & 496,1 & 86,6 & 73,2 & 83,7 \\
\hline
\end{tabular}

A eficiência média, no período de estudo, foi de $73,2 \%$, estando próxima à encontrada por Alves \& Ferreira (1998) (72\%), acima da observada por Cechin (2000) (68\%) e abaixo da verificada por Lopes et al. (2007) (80,3\%), superando a mínima recomendada pela literatura (Machado 1989). A eficiência operacional encontrada pode ser considerada satisfatória, contudo, é possível aumentá-la, reduzindo as horas em que as máquinas ficaram paradas e, consequentemente, aumentando as horas de trabalho efetivo.

A eficiência de um sistema de colheita de madeira depende, basicamente, do ambiente de trabalhado, tendo como principais fatores o clima, o terreno, a espécie vegetal, a infraestrutura, o nível de desenvolvimento, a tradição do sistema utilizado e a estrutura da indústria (Anderson \& Laestadius 1987, Malinovski \& Liotto 1992, Malinovski \& Malinovski 1998). Para aumentar a eficiência das máquinas e equipamentos, na colheita florestal, é necessário conhecer os motivos que ocasionam as perdas de tempo nas atividades, realizar periodicamente manutenções preventivas, planejar adequadamente o sistema de colheita de madeira e diminuir o tempo que estas máquinas ficam paradas (Cechin 2000).

A menor eficiência operacional foi observada no mês de outubro/2010, devido à baixa quantidade de horas efetivas de trabalho das máquinas (Tabela 1). Este resultado está relacionado com o início das operações de colheita florestal mecanizada pela empresa, caracterizando-se como um período de adaptação, com o treinamento dos operadores das máquinas e frequentes falhas de comunicação entre as equipes de manutenção, operadores e técnicos.

$\mathrm{Na}$ primavera, observou-se menor quantidade de horas trabalhadas pelas máquinas, cerca de $12 \%$ (60 horas), em relação ao que foi programado (496 horas), e menor quantidade de horas efetivas de trabalho, influenciando na eficiência operacional, que foi a mais baixa, dentre as quatro estações analisadas (Tabela 2). Apesar de não significativo, este resultado pode estar relacionado aos altos níveis de precipitação, durante a estação (cerca de $504 \mathrm{~mm}$ ). No verão e outono, as horas trabalhadas ultrapassaram as programadas e, no inverno, ficou em 489,6 horas (apenas 7 horas a menos que o programado).

As máquinas ficaram menos tempo paradas na primavera $(95,3$ horas; $\mathrm{p}<0,05)$, em relação ao verão (122,8 horas), outono (128,1 horas) e inverno (122,1 horas) (Tabela 2). Esta menor quantidade de horas paradas pode estar relacionada à efetividade da equipe de campo, à realização de reparos mais eficientes e, principalmente, ao menor tempo gasto para o deslocamento, em virtude da maior proximidade dos talhões de corte, na época da colheita, diminuindo o tempo gasto com o transporte das máquinas e da equipe de apoio.

As Harvesters apresentaram maior quantidade de horas paradas no verão, outono e inverno. Isto pode ser justificado pelo fato de as máquinas operarem mais, nestas estações (367,5 a 373,4 horas) (Tabela 2), o que, consequentemente, demanda maior tempo de interrupção das atividades, devido às maiores necessidades de manutenções necessárias ao bom 
Tabela 2. Valores médios estacionais de horas totais (HT), horas efetivas (HE), horas paradas (HP) e horas programadas (HPr) de trabalho, disponibilidade mecânica (DM) e eficiência operacional (E) de Harvesters utilizadas na colheita florestal e precipitação pluvial acumulada (BA, 2010/2011).

\begin{tabular}{|c|c|c|c|c|c|c|c|}
\hline \multirow{2}{*}{$\begin{array}{c}\text { Estação } \\
\text { do ano }\end{array}$} & HT & $\mathrm{HE}$ & $\mathrm{HP}$ & $\mathrm{HPr}$ & $\mathrm{DM}$ & $\mathrm{E}$ & \multirow{2}{*}{$\frac{\text { Precipitação }}{\mathrm{mm}}$} \\
\hline & \multicolumn{4}{|c|}{ horas } & \multicolumn{2}{|c|}{$\%$} & \\
\hline Primavera & $436,0 \mathrm{~b}$ & $340,7 \mathrm{a}$ & $95,3 \mathrm{~b}$ & $496,0 \mathrm{a}$ & $89,2 \mathrm{a}$ & $68,7 \mathrm{a}$ & 504,3 \\
\hline Verão & $496,2 \mathrm{a}$ & $373,4 \mathrm{a}$ & $122,8 \mathrm{a}$ & $496,0 \mathrm{a}$ & $83,3 \mathrm{a}$ & $75,3 \mathrm{a}$ & 361,4 \\
\hline Outono & $499,2 \mathrm{a}$ & $371,1 \mathrm{a}$ & $128,1 \mathrm{a}$ & $496,0 \mathrm{a}$ & $82,8 \mathrm{a}$ & $74,8 \mathrm{a}$ & 90,4 \\
\hline Inverno & $489,6 \mathrm{a}$ & $367,5 \mathrm{a}$ & $122,1 \mathrm{a}$ & $496,6 \mathrm{a}$ & $84,4 \mathrm{a}$ & $74,0 \mathrm{a}$ & 48,7 \\
\hline
\end{tabular}

Médias seguidas de mesma letra, na coluna, não diferem entre si, a 5\%, pelo teste Tukey.

desempenho no campo. Os demais parâmetros do desempenho operacional e eficiência não apresentaram diferenças significativas, em função das estações do ano (Tabela 2), com exceção das horas totais de trabalho das máquinas, que foram estatisticamente menores na primavera, em relação às demais estações do ano, em função das reduzidas horas efetivas (não significativo) e paradas (significativo), nesta estação.

Do total de horas de trabalho, de $22 \%$ a $26 \%$ do tempo, as máquinas ficaram paradas, nas quatro estações do ano. Dentre as atividades que integram o tempo improdutivo estão as de ordem técnica, como as horas em que as máquinas ficaram paradas por estarem aguardando peças, e o tempo de deslocamento de um talhão para o outro, representando 534,7 horas paradas, no período analisado (Tabela 3 ). As máquinas permaneceram cerca de 321 horas, ou seja, $29 \%$ do total de horas paradas, aguardando o deslocamento, pois são deslocadas para outro talhão de corte por meio de pranchas que, nem sempre, estão prontamente disponíveis para realizar a operação, o que acarreta aumento do tempo improdutivo. Pela sua natureza, estas interrupções são passíveis de redução, o que resultaria em aumento da capacidade de produção, pelo incremento da eficiência operacional.

Tabela 3. Total de horas paradas da Harvester utilizada na colheita florestal, em função da estação do ano e motivos (BA, 2010/2011).

\begin{tabular}{lcccr}
\hline \multirow{2}{*}{$\begin{array}{c}\text { Estação } \\
\text { do ano }\end{array}$} & $\begin{array}{c}\text { Aguardando } \\
\text { peça }\end{array}$ & $\begin{array}{c}\text { Aguardando } \\
\text { deslocamento }\end{array}$ & Deslocamento & Outros \\
\cline { 2 - 5 } & \multicolumn{4}{c}{ horas } \\
\hline Primavera & 18,2 & 81,6 & 33,2 & 32,4 \\
Verão & 77,5 & 62,3 & 69,6 & 109,4 \\
Outono & 68,1 & 89,3 & 70,0 & 70,3 \\
Inverno & 50,0 & 87,7 & 77,6 & 124,3 \\
\hline Total & 213,8 & 320,9 & 250,4 & 336,4 \\
\hline
\end{tabular}

O tempo total de 213,8 horas, em que as máquinas permaneceram paradas aguardando peças, poderia ser reduzido consideravelmente, por meio da redução do tempo de deslocamento destas da base para o campo, incluindo a melhoria nos processos de comunicação interna da empresa.

O tempo total gasto com o deslocamento das máquinas, de uma frente de trabalho para outra, atingiu 250,4 horas, nos 12 meses de avaliação (Tabela 3). Este tempo gasto, provavelmente, deu-se devido, também, à necessidade de deslocamento de todo o suporte de campo (caminhão de manutenção, restaurante, operadores e mecânicos).

Os demais motivos das paradas, manutenções corretivas e preventivas das máquinas (31\%), passagens de turno (13\%), espera pelo técnico (26\%) e refeições dos operadores (30\%), classificados como "outros", foram agrupados, pois, individualmente, não representavam horas significativas de paradas. Porém, a análise em conjunto destes motivos representou o maior tempo de parada das máquinas no estudo: cerca de 336 horas (Tabela 3 ).

\section{Desempenho operacional e eficiência da Forwarder}

Com relação ao desempenho operacional e eficiência das máquinas Forwarder, verificou-se que as mesmas apresentaram média de horas totais de trabalho de 481 horas e 36 minutos, sendo $84,7 \%$ (407,9 horas) de horas efetivas de trabalho e 15,3\% ( 73,7 horas) de horas paradas. A média de horas totais de trabalho foi $3 \%$ menor que as 496 horas programadas para o período de outubro de 2010 a setembro de 2011. Apesar disto, nos meses de fevereiro, abril, junho, agosto e setembro de 2011, as máquinas trabalharam mais do que o programado (Tabela 4).

A disponibilidade mecânica média da For-warder foi de $92 \%$, estando acima do encontrado por 
Tabela 4. Valores médios mensais das horas totais (HT), horas efetivas (HE), horas paradas (HP) e horas programadas (HPr) de trabalho, disponibilidade mecânica (DM) e eficiência operacional (E) de Forwarders utilizadas na colheita florestal e precipitação pluvial acumulada (BA, 2010/2011).

\begin{tabular}{|c|c|c|c|c|c|c|c|}
\hline \multirow{2}{*}{ Período } & HT & $\mathrm{HE}$ & $\mathrm{HP}$ & $\mathrm{HPr}$ & $\mathrm{DM}$ & E & \multirow{2}{*}{$\frac{\text { Precipitação }}{\mathrm{mm}}$} \\
\hline & \multicolumn{4}{|c|}{ horas } & \multicolumn{2}{|c|}{$\%$} & \\
\hline Out/2010 & 320,0 & 287,4 & 32,6 & 496,0 & 97,0 & 57,9 & 207,6 \\
\hline Nov/2010 & 496,0 & 436,5 & 59,5 & 496,0 & 95,5 & 88,0 & 219,1 \\
\hline Dez/2010 & 492,0 & 435,7 & 56,3 & 496,0 & 97,3 & 87,8 & 77,6 \\
\hline $\operatorname{Jan} / 2011$ & 490,8 & 393,8 & 97,0 & 496,0 & 80,3 & 79,4 & 40,8 \\
\hline Fev/2011 & 523,5 & 451,8 & 71,7 & 496,0 & 94,2 & 91,1 & 28,5 \\
\hline Mar/2011 & 469,0 & 390,4 & 78,7 & 496,0 & 90,3 & 78,7 & 292,1 \\
\hline $\mathrm{Abr} / 2011$ & 526,0 & 448,9 & 77,1 & 496,0 & 93,7 & 90,5 & 64,9 \\
\hline Mai/2011 & 482,5 & 403,4 & 79,1 & 496,0 & 91,2 & 81,3 & 23,7 \\
\hline Jun/2011 & 503,0 & 395,0 & 108,0 & 496,0 & 85,5 & 79,6 & 1,8 \\
\hline Jul/2011 & 480,0 & 417,7 & 62,3 & 496,0 & 95,4 & 84,2 & 28,7 \\
\hline Ago/2011 & 498,5 & 413,3 & 85,2 & 496,0 & 93,2 & 83,3 & 18,0 \\
\hline Set/2011 & 498,0 & 421,1 & 76,9 & 498,0 & 90,9 & 84,6 & 2,0 \\
\hline Média & 481,6 & 407,9 & 73,7 & 496,2 & 92,0 & 82,2 & 83,7 \\
\hline
\end{tabular}

Fiedler et al. (2008) (90\%). Aumentar a disponibilidade de uma máquina implica em reduzir o número de falhas ocorridas, aumentar a rapidez com que estas são corrigidas e melhorar os procedimentos de trabalho e logística, bem como a interdependência destes fatores (Fontes \& Machado 2002). A menor disponibilidade mecânica foi observada no mês de janeiro de 2011, devido a problemas mecânicos que demandaram a espera de mão de obra especializada e peças de reposição.

A eficiência média no período foi de $82,2 \%$ (Tabela 4), semelhante à obtida por Simões \& Fenner (2010) (82\%). Os maiores valores de eficiência operacional foram encontrados nos meses de fevereiro e abril de 2011, caracterizados por poucas chuvas, o que pode ter facilitado o deslocamento das máquinas, dentro do talhão.

A primavera foi a estação do ano com menor quantidade de horas trabalhadas, que, apesar de não significativa, corresponde a menos de 60 horas do total programado (Tabela 5). Este resultado pode estar relacionado ao observado para as máquinas Harvester, que, também, apresentaram menor rendimento nesta estação (Tabela 2), refletindo, assim, na extração da madeira. Da mesma forma, no outono, as horas de trabalho ultrapassaram em, aproximadamente, 8 horas a meta programada, caracterizando-se como o período em que as máquinas mais trabalharam, em consequência, também, da quantidade de horas trabalhadas pela Harvester (Tabela 2). As máquinas ficaram menos tempo paradas na primavera (49,5 horas; $\mathrm{p}<0,05)$, se comparada ao verão ( 82,5 horas), outono (88,1 horas) e inverno (74,8 horas) (Tabela 5). Os demais parâmetros do desempenho operacional e da eficiência não apresentaram diferenças significativas, em função das estações do ano (Tabela 5).

$\mathrm{Na}$ Tabela 6 é apresentado o total de horas em que as máquinas Forwarder ficaram paradas por mês, bem como os motivos que causaram estas paradas. Das 1.118 horas paradas, no período de um ano, $51 \%$

Tabela 5. Valores médios estacionais de horas totais (HT), horas efetivas (HE), horas paradas (HP) e horas programadas (HPr) de trabalho, disponibilidade mecânica (DM) e eficiência operacional (E) de Forwarders utilizadas na colheita florestal e precipitação pluvial acumulada no período (BA, 2010/2011).

\begin{tabular}{|c|c|c|c|c|c|c|c|}
\hline \multirow{2}{*}{$\begin{array}{c}\text { Estação } \\
\text { do ano }\end{array}$} & HT & $\mathrm{HE}$ & $\mathrm{HP}$ & $\mathrm{HPr}$ & $\mathrm{DM}$ & E & Precipitação \\
\hline & \multicolumn{4}{|c|}{ horas } & \multicolumn{2}{|c|}{$\div \%$} & $\mathrm{~mm}$ \\
\hline Primavera & $436,0 \mathrm{a}$ & $386,5 \mathrm{a}$ & $49,5 \mathrm{~b}$ & $496,0 \mathrm{a}$ & $96,6 \mathrm{a}$ & 77,9 a & 504,3 \\
\hline Verão & 494,4 a & $412,0 \mathrm{a}$ & $82,5 \mathrm{a}$ & $496,0 \mathrm{a}$ & 88,3 a & $83,1 \mathrm{a}$ & 361,4 \\
\hline Outono & $503,8 \mathrm{a}$ & $415,8 \mathrm{a}$ & $88,1 \mathrm{a}$ & $496,0 \mathrm{a}$ & $90,1 \mathrm{a}$ & $83,8 \mathrm{a}$ & 90,4 \\
\hline Inverno & $492,2 \mathrm{a}$ & $417,3 \mathrm{a}$ & $74,8 \mathrm{a}$ & $496,7 \mathrm{a}$ & $93,2 \mathrm{a}$ & $84,0 \mathrm{a}$ & 48,7 \\
\hline
\end{tabular}

Médias seguidas de mesma letra, na coluna, não diferem entre si, a 5\%, pelo teste Tukey. 
Tabela 6. Total de horas paradas da Forwader utilizada na colheita florestal, em função da estação do ano e dos motivos elencados (BA, 2010/2011).

\begin{tabular}{lccc}
\hline & \multicolumn{3}{c}{ Principais motivos das paradas } \\
\cline { 2 - 4 } $\begin{array}{c}\text { Estação } \\
\text { do ano }\end{array}$ & $\begin{array}{c}\text { Manutenção } \\
\text { corretiva }\end{array}$ & $\begin{array}{c}\text { Manutenção } \\
\text { preventiva }\end{array}$ & Lubrificação \\
\cline { 2 - 4 } & \multicolumn{3}{|c}{ horas } \\
\hline Primavera & 56,7 & 16,1 & 10,4 \\
Verão & 142,2 & 118,3 & 58,3 \\
Outono & 220,4 & 169,6 & 41,4 \\
Inverno & 148,1 & 110,5 & 26,1 \\
\hline Total & 567,4 & 414,5 & 136,2 \\
\hline
\end{tabular}

referem-se ao tempo gasto com manutenção corretiva (567,4 horas). O tempo gasto com manutenção preventiva e lubrificação corresponderam a $37 \%$ e $12 \%$, respectivamente, das horas paradas. Normalmente, a manutenção preventiva é a maior causa das horas paradas, exceto em casos que envolvem a logística e a falta de peças, que não se incluem no caso relatado. A função da manutenção preventiva, juntamente com inspeções, é reduzir as paradas corretivas, que são indesejáveis, por não apresentarem previsibilidade. Desta forma, o planejamento das manutenções é fundamental para aumentar a eficiência das Forwarders (e das máquinas florestais, de maneira geral), uma vez que estas máquinas trabalham em locais isolados e distantes.

As Forwarders ficaram mais tempo paradas, realizando manutenção corretiva, no outono (220,4 horas), período de maior eficiência dos equipamentos e, consequentemente, maior esforço das máquinas (Tabela 6). É esperado que, em períodos de maior produtividade, haja a necessidade de se realizar mais manutenções no equipamento. Sem estas paradas, as máquinas, provavelmente, não suportariam os esforços exigidos. Este mesmo comportamento ocorreu, também, na primavera, com a baixa eficiência das máquinas e, consequentemente, menor parada para manutenção e lubrificação, uma vez que, neste período, a máquina operou em um total de apenas 436 horas.

\section{CONCLUSÕES}

1. As máquinas Harvester e Forwarder apresentaram eficiência operacional satisfatória e superior a 70\%, índice mínimo indicado para máquinas florestais utilizadas na colheita florestal.
2. O desempenho operacional das máquinas florestais mostrou-se adequado, em função da distribuição dos tempos, com $76 \%$ e $85 \%$ de tempo efetivo de trabalho para as máquinas Harvester e Forwarder, respectivamente, e da disponibilidade mecânica, com média de $89 \%$, para as duas máquinas florestais.

3. As interrupções operacionais tiveram importante influência no tempo total de trabalho das máquinas.

\section{REFERÊNCIAS}

ANDERSSON, S.; LAESTADIUS, L. Efficiency in highly mechanized wood harvesting systems. SIMPÓSIO SOBRE EXPLORAÇÃO, TRANSPORTE, ERGONOMIA E SEGURANÇA EM REFLORESTAMENTOS, 1., 1987, Curitiba. Anais... Curitiba: Fupef, 1987. p. 133-143.

ALVES, M. K. L.; FERREIRA, O. O. Avaliação da etapa de descasque de torretes de eucalipto para polpa. Ciência Florestal, Santa Maria, v. 8, n. 1, p. 1-12, 1998.

BAGIO, A. J.; STOHR, G. W. D. Resultados preliminares de um levantamento dos sistemas de exploração usados em florestas implantadas no Sul do Brasil. Revista Floresta, Curitiba, v. 9, n. 2, p. 76-96, 1978.

CECHIN, F. N. Análise da eficiência e do desempenho operacional das máquinas e dos equipamentos utilizados no corte raso de povoamentos florestais na região do planalto norte de Santa Catarina. 2000. 136 f. Dissertação (Mestrado em Engenharia Florestal)-Universidade Federal do Paraná, Curitiba, 2000.

EMPRESA BRASILEIRA DE PESQUISA AGROPECUÁRIA (Embrapa). Centro Nacional de Pesquisa do Solo. Sistema brasileiro de classificação de solos. Rio de Janeiro: Embrapa, 2006.

FIEDLER, N. C.; ROCHA, E. B. da; LOPES, E. da S. Análise da produtividade de um sistema de colheita de árvores inteiras no norte do Estado de Goiás. Revista Floresta, Curitiba, v. 38, n. 4, p. 577-586, 2008.

FONTES, J. M.; MACHADO, C. C. Manutenção mecânica. In: MACHADO, C. C. (Ed.). Colheita florestal. Viçosa: UFV, 2002. p. 243-291.

LEÃO, A. C.; MELO, A. O. Características morfológicas, físico-químicas e mineralógicas dos solos da estação ecológica de Pau-Brasil. Agrotrópica, Porto Seguro, v. 2, n. 2, p. 105-112, 1990.

LOPES, S. et al. Avaliação técnica e econômica do corte de madeira de pinus com cabeçote Harvester em diferentes condições operacionais. Revista Floresta, Curitiba, v. 37, n. 3, p. 305-313, 2007. 
MACHADO, C. C. Exploração florestal. Viçosa: UFV, 1989.

MACHADO, C. C. O setor florestal brasileiro. In: MACHADO, C. C. (Ed.). Colheita florestal. Viçosa: UFV, 2008. p. 15-42.

MACHADO, C. C.; LOPES, E. S. Análise da influência do comprimento de toras de eucalipto na produtividade e custo da colheita e transporte florestal. Revista Cerne, v. 6, n. 2, p. 124-129, 2000.

MALINOVSKI, J. R.; LIOTTO, V. G. Harvesting timber in Brazil: actual situation and future perspectives. Revista Setor de Ciências Agrárias, Curitiba, v. 24, n. 2, p. 35-47, 1992.

MALINOVSKI, J. R.; MALINOVSKI, R. A. Evolução dos sistemas de colheita de pinus na região Sul do Brasil. Curitiba: UFPR/Fupef, 1998.

NOVAES, A. B.; SÃO JOSÉ, A. R. Caracterização da região da mata de cipó no sudeste da Bahia. In: NOVAES, A. B. et al. Reflorestamento no Brasil. Vitória da Conquista: UESB, 1992. p. 7-16.
PELOIA, P. R.; MILAN, M. Proposta de um sistema de medição de desempenho aplicado à mecanização agrícola. Engenharia Agrícola, Jaboticabal, v. 30, n. 4, p. 681-691, 2010.

SAS INSTITUTE. SAS/STAT user's guide: version 6.08. Cary: SAS institute, 1997.

SILVA, C. B.; SANT'ANNA, C. M.; MINETTE, L. J. Avaliação ergonômica do "Feller-buncher" utilizado na colheita de eucalipto. Revista Cerne, Lavras, v. 9, n. 1, p. 109-118, 2003.

SILVA, E. N. et al. Avaliação técnica e econômica do corte mecanizado de Pinus sp. com Harvester. Revista Árvore, Viçosa, v. 34, n. 4, p. 745-753, 2010.

SIMÕES, D.; FENNER, T. P. Avaliação técnica e econômica do Forwarder na extração de madeira em povoamentos de eucalipto de primeiro corte. Revista Floresta, Curitiba, v. 40, n. 4, p. 711-720, 2010. 